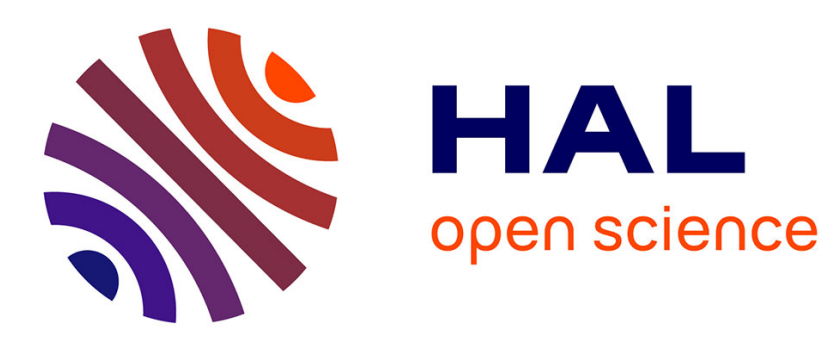

\title{
Dust-Cloud Dynamics in a Complex Plasma Afterglow
}

Lénaïc Couëdel, Alexander A. Samarian, Maxime Mikikian, Laifa Boufendi

\section{To cite this version:}

Lénaïc Couëdel, Alexander A. Samarian, Maxime Mikikian, Laifa Boufendi. Dust-Cloud Dynamics in a Complex Plasma Afterglow. IEEE Transactions on Plasma Science, 2008, 36 (4), pp.1014. 10.1109/TPS.2008.920220 . hal-00312548

\section{HAL Id: hal-00312548 \\ https://hal.science/hal-00312548}

Submitted on 25 Aug 2008

HAL is a multi-disciplinary open access archive for the deposit and dissemination of scientific research documents, whether they are published or not. The documents may come from teaching and research institutions in France or abroad, or from public or private research centers.
L'archive ouverte pluridisciplinaire HAL, est destinée au dépôt et à la diffusion de documents scientifiques de niveau recherche, publiés ou non, émanant des établissements d'enseignement et de recherche français ou étrangers, des laboratoires publics ou privés. 


\title{
Dust-Cloud Dynamics in a Complex Plasma Afterglow
}

\author{
Lénaïc Couëdel, Alexandre A. Samarian, Maxime Mikikian, and Laïfa Boufendi
}

\begin{abstract}
The motion of a dust-particle cloud in the afterglow of a complex plasma is reported. It is shown that the dust-particle charges strongly affect the dynamic behavior of the dust cloud. Consequently, using the analysis of the whole cloud motion to deduce dust residual-charge and plasma-diffusion parameters is proposed.
\end{abstract}

\section{Index Terms-Charge, dust cloud, dusty plasma.}

A COMPLEX (dusty) plasma is a partially ionized gas in which there are some charged dust particles. They are very common media and can be either natural plasmas (such as comet tails, planetary ring, and near-Earth plasmas) or humanmade plasmas (such as tokamak-edge plasma, etching plasmas, and plasma-enhanced chemical vapor deposition). In laboratory discharges, the dust particles are negatively charged due to a higher mobility of the electrons [1], [2].

The dust particles can be either grown or injected directly into the plasma. Injected dust particles are generally micrometer sized, and thus, they are confined in the sheath region above the lower electrode where the force due to the electric field can balance the gravity force. Consequently, microgravity conditions are needed to observe a cloud of injected particles filling up the whole discharge chamber [3]. On the other hand, dust particles grown directly in the plasma are light enough to fill the whole interelectrode space, and dense clouds of dust particles can be observed and can form structures, such as the dust void, in onground experiments [4]. Dust particles can be grown by using reactive gases (such as silane [5] or methane [6]) or by sputtering a target with the ions coming from the plasma [7], [8].

The dust-particle charge is a very important parameter for complex plasmas. It determines the interaction of a dust particle with its neighboring dust particles and the ions and electrons of the surrounding plasma. Consequently, the determination of the dust-particle charge is one of the most important measurements in any complex plasma experiment.

Manuscript received November 28, 2007; revised February 13, 2008. This work was supported in part by CNES under contract 793/2000/CNES/8344 and in part by the French-Australian integrated research program (FAST) under Contract FR060169.

L. Couëdel is with the School of Physics, The University of Sydney, Sydney, N.S.W. 2006, Australia, and also with the Groupe de Recherches sur l'Energétique des Millieux Ionisés, Centre National de la Recherche Scientifique-Université d'Orléans, 45067 Orléans Cedex 2, France.

A. A. Samarian is with the School of Physics, The University of Sydney, Sydney, N.S.W. 2006, Australia.

M. Mikikian and L. Boufendi are with the Groupe de Recherches sur l'Energétique des Millieux Ionisés, Centre National de la Recherche Scientifique-Université d'Orléans, 45067 Orléans Cedex 2, France.

Color versions of one or more of the figures in this paper are available online at http://ieeexplore.iee.org.

Digital Object Identifier 10.1109/TPS.2008.920220
In a decaying complex plasma, the electrons and ions of the plasma are lost by diffusion to the walls of the reactor and by recombination on the dust-particle surfaces. Consequently, the charge carried by the dust particles evolves with the other plasma parameters during the plasma afterglow. As the dustcharging time depends strongly on the electron and ion densities [1], the dust-particle charging time becomes very long in the late plasma afterglow, and the dust-particle charges are considered frozen. It has thus been shown that in the late afterglow of a complex plasma, dust particles indeed keep a residual charge of a few elementary charges and that positively charged, negatively charged, and neutral dust particles coexist for several minutes after the power of the discharge is turned off [9], [10].

In a complex plasma afterglow, the dust-cloud motion will be affected by the dust residual charges due to the involved electrostatic interactions. By recording the motion of a dust cloud in the afterglow of a complex plasma, it is thus possible to deduce some important parameters such as the dust-particle mean charge and the remanent electric fields. In this paper, the motion of a dust-particle cloud in the afterglow of an RF discharge is reported.

The experiment has been done in the plasma kristal experiment (PKE)-Nefedov reactor [3]. It is an RF discharge operating in a push-pull excitation mode. The electrodes are parallel and are $4 \mathrm{~cm}$ in diameter. They are separated by a gap of $3 \mathrm{~cm}$. The injected power is in the range of $0-4 \mathrm{~W}$. The dust particles were grown in an argon plasma (0.2-2 mbar). A thin laser sheet that is perpendicular to the electrodes was used to illuminate the dust particles, and the scattered light was recorded at an angle $\Theta \sim 30^{\circ}$ with a fast charge-coupled device camera with 500 frames/s.

Frames from the video taken at different times of the complex plasma afterglow are shown in Fig. 1. As it can be seen when the discharge is on $(t<0)$, the interelectrode space is filled with a cloud of dust particles in which a dust-free region called a "void" can be observed. This void is a common feature of complex plasmas [1]-[4]. The intensity of the scattered light of the column going through the center of the void is also shown in Fig. 1 (3-D plot). It shows its evolution with time and, thus, the evolution of the dust density. A similar method was used in [4] to study dust-cloud dynamics in a running discharge. The void is clearly observed because it corresponds to a strong drop in the scattered light intensity. Video frames can also be used to extract dust-particle trajectories (not presented here).

When the discharge is turned off, the dust cloud starts to fall down due to the gravity (in Fig. 1, frames for $t>0$ ). Nevertheless, it can be seen that in the first $20 \mathrm{~ms}$ after the 

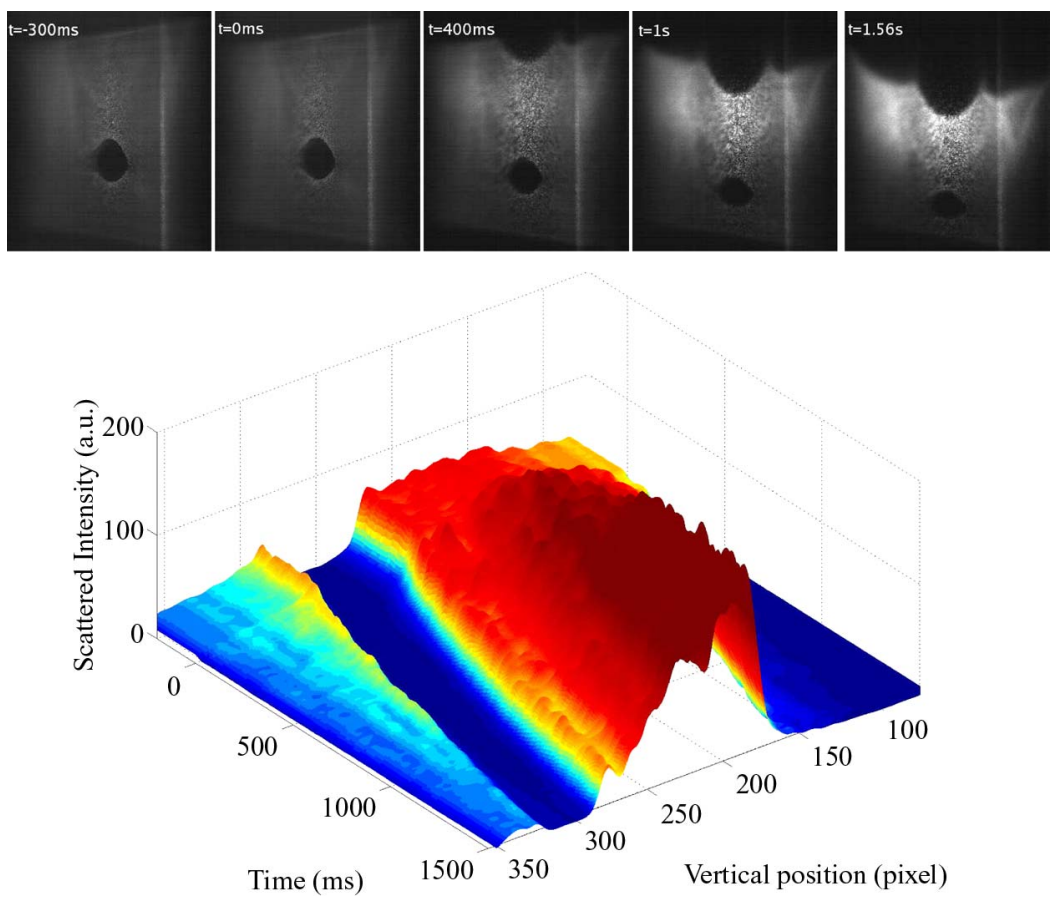

Fig. 1. (Top) Frames extracted from the video of the laser scattered light during the plasma afterglow. (Bottom) Evolution of the scattered intensity of the central column going through the center of the dust void. The zero coordinate in the vertical position corresponds to the top of the picture. The discharge was switched off at $t=0 \mathrm{~ms}$.

discharge is switched off, the scattered light intensity increases drastically. As the scattered light is roughly proportional to the dust density, it indicates that the dust cloud contracts at the very beginning of the plasma decay. The time scale of this contraction $\left(t_{c} \leq 20 \mathrm{~ms}\right)$ is too short to be explained by the gravity force. Consequently, it implies the action of the confining electric field. This electric field confines the dust cloud inside the plasma when the discharge is on while the dust particles tend to repel each other. When the RF generator is turned off, the RF field decreases, and the confining electric field evolves, too. During this time, the electron temperature relaxes to room temperature, leading to a drastic drop of the dust charge [9]. The dust-particle cloud thus contracts due to the changes in the repelling and confining forces. Knowing the dust-particle charge evolution and looking at the dustcloud dynamics, an estimation of the evolution of the confining electric field may be done.

Another feature of the dust-cloud dynamics in the plasma afterglow is the evolution of the dust void. As it is shown in Fig. 1, the dust void remains well defined with a sharp boundary for a very long time.

To conclude, the analysis of the motion of the dust cloud could give information about dust residual charges, diffusion processes, and electric fields because the dust-cloud dynamics is strongly affected by the dust-particle charges.

\section{ACKNOWLEDGMENT}

The authors would like to thank S. Dozias and B. Dumax for the electronic support, J. Mathias for the optical support, and Y. Tessier for the experimental support. The PKENefedov chamber has been made available by the MaxPlanck-Institut für extraterrestrische Physik, Germany, under the funding of the Deutsches Zentrum für Luft- und Raumfahrt/Bundesministerium für Bildung und Forschung under Grant 50WM9852.

\section{REFERENCES}

[1] S. Vladimirov, K. Ostrikov, and A. Samarian, Physics and Applications of Complex Plasmas. London, U.K.: Imperial Press, 2005.

[2] A. Bouchoule, Dusty Plasmas: Physics, Chemistry and Technological Impacts in Plasma Processing. New York: Wiley, 1999.

[3] A. P. Nefedov, G. E. Morfill, V. E. Fortov, and H. M. Thomas et al., "PKENefedov: Plasma crystal experiments on the international space station," New J. Phys., vol. 5, p. 33, 2003.

[4] M. Mikikian, L. Couëdel, M. Cavarroc, Y. Tessier, and L. Boufendi, "Selfexcited void instability in dusty plasmas: Plasma and dust cloud dynamics during the heartbeat instability," New J. Phys., vol. 9, p. 268, 2007.

[5] M. Cavarroc, M. Mikikian, G. Perrier, and L. Boufendi, "Single-crystal silicon nanoparticles: An instability to check their synthesis," Appl. Phys. Lett., vol. 89, no. 1, p. 013 107, Jul. 2006.

[6] H. T. Do, G. Thieme, M. Fröhlich, H. Kersten, and R. Hippler, "Ion molecule and dust particle formation in $\mathrm{Ar} / \mathrm{CH}_{4}, \mathrm{Ar} / \mathrm{C}_{2} \mathrm{H}_{2}$ and $\mathrm{Ar} / \mathrm{C}_{3} \mathrm{H}_{6}$ radiofrequency plasmas," Contrib. Plasma Phys., vol. 45, no. 5/6, pp. 378-384, Aug. 2005.

[7] M. Mikikian et al., "Formation and behaviour of dust particle clouds in a radio-frequency discharge: Results in the laboratory and under microgravity conditions," New J. Phys., vol. 5, p. 19, 2003.

[8] D. Samsonov and J. Goree, "Particle growth in a sputtering discharge," J. Vac. Sci. Technol. A, Vac. Surf. Films, vol. 17, no. 5, pp. 2835-2840, Sep. 1999.

[9] L. Couëdel, M. Mikikian, L. Boufendi, and A. A. Samarian, "Residual dust charges in discharge afterglow," Phys. Rev. E, Stat. Phys. Plasmas Fluids Relat. Interdiscip. Top., vol. 74, no. 2, p. 026 403, Aug. 2006.

[10] A. Ivlev et al., "Decharging of complex plasmas: First kinetic observations," Phys. Rev. Lett., vol. 90, no. 5, p. 055003 , Feb. 2003. 